\title{
Students Acceptance of Google Classroom: An Exploratory Study using PLS-SEM Approach
}

\author{
https://doi.org/10.3991/ijet.v13i06.8275 \\ Rana A. Saeed Al-Maroof $\left({ }^{\square}\right)$ \\ Al Buraimi University College, Al Buraimi, Oman \\ rana@buc.edu.om \\ Mostafa Al-Emran \\ Universiti Malaysia Pahang, Pahang, Malaysia \\ Al Buraimi University College, Al Buraimi, Oman
}

\begin{abstract}
Google classroom can work in unidirectional process as it can serve the teachers' strategies and styles on one hand and students' perception, understanding, and effective participation in different classroom skills on the other hand. The acceptance of Google classroom is affected by different factors. Some of them are still not clearly specified and discussed in previous research; therefore, they need further investigation. Based on the previous assumption, this study is an attempt to examine the factors that affect the students' acceptance of Google classroom at Al Buraimi University College (BUC) in Oman. The Technology Acceptance Model (TAM) was adopted to formulate the hypotheses of the current study. The data was collected through an online questionnaire with 337 respondents. The Partial Least Square-Structural Equation Model (PLS-SEM) approach was used to assess both the measurement and structural models. The results of the study prove that both the perceived ease of use (PEOU) and perceived usefulness (PU) positively influence the behavioral intention, which in turn influence the actual usage of Google classrooms. This study helps the decision makers of the higher educational institutions to have a better understanding of the effectiveness of using Google classroom by their students. It is assumed that it helps in measuring the level of students' acceptance to the previously mentioned technology.
\end{abstract}

Keywords-Google classroom, acceptance, PLS-SEM, TAM

\section{Introduction}

The distance, online or blending learning style of teaching offers many advantages over the traditional classroom teaching style. The most influential advantages lie in its accessibility, students' scheduling flexibility, and adaptability for working [1]. Google classroom is a kind of blending way of learning that was initiated in 2014. It takes into consideration the achievement of specific functions such as simplifying the students-teacher communication, and the ease of distributing and grading assignments. It provides the students with an opportunity to submit their work to be graded 
by their teachers online within the deadlines. Similarly, teachers can have a complete vision concerning the progress of each student, and they can return work along with the necessary comments so that the student can revise their assignments.

Accordingly, Google classroom can be effective for both the learners and faculty members due to its features. As for the students, it provides a stream line of communication and workflow for students. Being free of paper is a crucial factor in developing learning strategies. Thus, students can keep their files more organized and need less stored paperless in a single program [2]. The previously given view is supported by [3] who points out that Google classroom is useful in facilitating teaching and learning process. Students are able to use it with ease whenever the need arises. The teachers' most important task is to make students aware of the way of using the apps. The main purpose of this paper is to study the factors that affect the Google classroom acceptance among undergraduates' students at Al Buraimi University College in Oman.

The rest of this paper is organized as follows: section two provides a summary about the relevant studies that were carried out concerning Google classroom. Section three shows the research hypotheses. Section four illustrates the research methodology. The results and discussion are provided in section five. Finally, section six demonstrates the conclusion and future work.

\section{$2 \quad$ Literature Review}

There have been lots of research papers that are related to an e-learning, online or blending learning, the number of research papers that focuses on Google classroom as a means of learning are still limited, though. One of the most recent studies by [4] who make use of a unified theory of acceptance and use of technology 2 (UTAUT2) model to investigate the main factors that affect the implementation of Google Classroom in specific courses. The survey with 24 five-point Likert-scale questions was collected from students who enrolled in these courses. The main findings support the fact that Google classroom can enhance the students' self-directed learning (SDL) cognitive skills. The study makes use of 'The Google Form questionnaires' as a tool to measure the level of users' satisfaction and self-evaluation. Additionally, it makes use the assessment in term of grading.

The Google classroom is available as a tool for developing teaching and learning process all over the world. A study that has implemented in Bangladesh tries to investigate the importance of this e-learning tool for both students and faculty members. It focuses on certain factors that rely behind the poor engagement of students in Google classroom. The most important findings emphasize the fact that students prefer the engagement in Google classroom where the teachers have passive roles rather than being engaged in a class where the teachers have more active roles. However, when the Google classroom is compared with Facebook, the Google classroom suffers from certain limitations [5]. The results are collected from a questionnaire that has been developed to serve the same purpose. In this respect, it has been stated that "The analysis of the results of the questionnaire indicate that this study can be effective in un- 
derstanding and evaluating teachers' and learners' perceptive to ensure quality teaching and learning through Google classroom" [5]. Google classroom can have an effective role in developing the learning abilities of with learning disabilities as it is shown in a study by [6] who proposes that the Google classroom can be effective in social studies and it can improve students' learning abilities in the field of vocabulary development and unit-test. The study shows that although the students can increase the number of the vocabulary, but they still suffer from certain limitation at the level of content knowledge in comparison with the knowledge obtained based on the textbook and printed material as teaching resources.

Within the domain of self-learning and self-development, a study carried by [7] who put more emphasis on the role of Google classroom as a self-directed learning tool in chosen courses. It has been found that self-satisfaction on the students' behalf is evident when it comes to the usage of Google classroom due to its usefulness, easy to use, and its practicality in accomplishing the intended tasks. Accordingly, Google Classroom can be used as an effective tool in active learning. This view is supported by [3] where the paper shows that teachers can constantly control their observations, surveys, and analyses of student demography through Google classroom technology. They can design their courses to suit students' satisfaction on the used method of learning. The effective use of online learning technology can pave the way to a better design of online training courses for instructors and educational support programs that allow students to succeed in the online environment. This implies that Google classroom can be integrated with other software such as data mining to increase the chances of flexible usage.

Based on the available research studies, it has been observed that there is a limited number of research articles that examined the factors that affect the Google classroom acceptance among university students in general, and the Gulf region countries in particular. According to [8]-[11], BUC has become one of the growing Colleges in Oman that is keen on providing a reliable technological environment to their students and faculty members. Recently, BUC has implemented the Google classroom in all its departments creating a need to investigate the role of the factors that can influence the students' acceptance of Google classroom through an empirical study. Thus, the main objective of this study is to examine the factors that affect the Google classroom acceptance by undergraduates' students at BUC.

\section{Theoretical framework and research hypotheses}

There are various information system (IS) theories/models that were developed to study the acceptance of new technology. One of such well-known models is the Technology Acceptance Model (TAM) that was developed by Davis in 1989 [12]. TAM has been developed based on the Theory of Reasoned Action (TRA) [13]. TAM suggests that the student's behavioral intention to use Google classroom is determined by two main beliefs; perceived usefulness (PU) and perceived ease of use (PEOU). PU refers to the degree to which a person believes that using a particular system would enhance his/her job performance, whereas, PEOU refers to the degree to which 
a person believes that using a particular system would be free from efforts. Various scholars have adopted the TAM to study the technology acceptance and usage. For instance, it has been successfully adopted in similar contexts like E-learning [14] and M-learning [15].

In the present study, the TAM [12] is adopted for measuring the students' acceptance of Google classroom as a technology in their daily academic lesson. In this respect, TAM provides a solid background for the effectiveness of a new technology. Besides, TAM also suggests that when students are exposed to a new technology, many factors can influence their acceptance decision. Based on that, we are interested in testing the following hypotheses:

H1: Perceived ease of use positively influences the perceived usefulness of Google classroom.

H2: Perceived ease of use positively influences the behavioral intention to use Google classroom.

H3: Perceived usefulness positively influences the behavioral intention to use Google classroom.

H4: Behavioral intention to use influences the actual use of Google classroom.

\section{$4 \quad$ Research Methodology}

\subsection{Context and subjects}

The study was conducted at Al Buraimi University College (BUC) in Oman. By the end of 2016, BUC has evolved the initiative of implementing the Google classroom in all its departments. The sample of this study consists of students who have used the Google classroom in their study from different departments at BUC. A total of 305 valid responses were received from a total of 337 questionnaires administrated, which shows a response rate of $90.5 \%$.

\subsection{Survey instrument}

An online questionnaire survey was sent to all the enrolled students on the first semester of the academic year 2017-2018 for the purpose of data collection. The survey consists of 3 different parts. The first part aims to collect the students' demographic information. The second part is dedicated to collect data regarding the Google classroom usage. The third part is devoted to collect data regarding the Technology Acceptance Model (TAM) factors. These factors include: the perceived usefulness (PU), the perceived ease of use (PEOU), the behavioral intention (BI), and the actual use (AU). The items used for this study were adopted from [12] with further adjustment to fit the scope of this study. Appendix A shows the constructs' items. 


\subsection{Data Analysis}

In the present study, the Partial Least Squares-Structural Equation Modelling (PLS-SEM) using SmartPLS 3 is used for the statistical analysis [16]. Besides, since this study is an exploratory based-research, PLS-SEM is considered the suitable approach for such type of studies [17]. In terms of the measurement model, [17] suggested that scholars should consider the outer loadings of the items and the average variance extracted (AVE) in order to establish the convergent validity. In addition, [17] suggested two measures for establishing a discriminant validity namely: cross loading and Fornell-Larcker criterion. Moreover, [18] suggested examining the Heterotrait-Monotrait as another criterion for assessing the discriminant validity. In terms of the structural model, the path coefficients and the coefficient of determination $\left(R^{2}\right)$ will be measured [17]. Accordingly, we will apply all the aforementioned criteria in order to assess the measurement and structural models.

\section{$5 \quad$ Results and Discussion}

\subsection{Descriptive statistics}

The sample demonstrates the responses collected from BUC students which were 337 in total. Nevertheless, the usable responses after removing the missing values and outliers are 305 . In addition, Table 1 shows the demographic information of the participants. We can observe that females constitute $74 \%$ of the collected data while only $26 \%$ as males. Furthermore, most of the students are aged between 18 and 22 years, which represent $79 \%$ of the sample. In terms of department, $41 \%$ of the students are from the Business Administration \& Accounting; this is followed by 35\% from the English Language, 17\% from the Information Technology, and 7\% from the Law, respectively. With regard to the year of study, it is clearly shown that $37 \%$ of the participants are year 1 , followed by $31 \%$ as year $2,16 \%$ for both year 3 and year 4 , respectively.

In terms of the Google classroom usage, results showed that $66 \%$ of the participants have less than 3 months as experience in using the Google classroom in their education. Additionally, findings revealed that $75 \%$ of the students are using the Google classroom in their pedagogical process. Furthermore, results indicated that $59 \%$ of the students are favoring both (Google classroom learning and traditional learning) in their education, followed by $21 \%$ of those who preferred the Google classroom, and $20 \%$ for those who preferred the traditional learning, respectively. 
Table 1. Demographic information

\begin{tabular}{|l|l|c|c|}
\hline \multicolumn{1}{|c|}{ Item } & \multicolumn{1}{|c|}{ Values } & Frequency & Percentage \\
\hline \multirow{3}{*}{ Gender } & Male & 78 & $26 \%$ \\
\cline { 2 - 4 } & Female & 227 & $74 \%$ \\
\hline \multirow{4}{*}{ Age } & 18 to 22 & 242 & $79 \%$ \\
\cline { 2 - 4 } & 23 to 28 & 35 & $12 \%$ \\
\cline { 2 - 4 } & Above 28 & 28 & $9 \%$ \\
\hline \multirow{5}{*}{ Department } & English Language & 106 & $35 \%$ \\
\cline { 2 - 4 } & Business Administration \& Accounting & 125 & $41 \%$ \\
\cline { 2 - 4 } & Information Technology & 53 & $17 \%$ \\
\cline { 2 - 4 } & Law & 21 & $7 \%$ \\
\hline \multirow{5}{*}{ Year of study } & Year 1 & 114 & $37 \%$ \\
\cline { 2 - 4 } & Year 2 & 94 & $31 \%$ \\
\cline { 2 - 4 } & Year 3 & 49 & $16 \%$ \\
\cline { 2 - 4 } & Year 4 & 48 & $16 \%$ \\
\hline
\end{tabular}

\subsection{Measurement Model Assessment}

In order to measure the reliability of each item, the factor loading should be measured. According to [17], a threshold value of equal or greater than 0.7 for each item's loading is considered as reliable. In addition, the Cronbach's Alpha and composite reliability values should be equal or greater than 0.7 . Based on Table 2, we can observe that all the items are reliable and satisfy the set criteria with an exception for PU6 and PU7 which their factor loadings were below 0.7 and therefore, PU6 and PU7 were removed from the construct's structure. Besides, the average variance extracted (AVE) is defined as the grand mean value of the squared loadings of the items related to the construct, and the common measure for establishing the convergent validity. A value of 0.5 or greater for the AVE specifies that the construct elucidates more than half of the variance of its items [17]. As shown in Table 2, the Cronbach's Alpha and composite reliability values are greater than 0.7 , and the AVE values are greater than 0.5 . Thus, the constructs' convergent validity is established. 
Table 2. Measurement Model Results

\begin{tabular}{|c|c|c|c|c|c|}
\hline Constructs & Items & Loadings & $\begin{array}{c}\text { Cronbach's } \\
\text { Alpha }\end{array}$ & $\begin{array}{l}\text { Composite } \\
\text { reliability }\end{array}$ & $\begin{array}{c}\text { Average } \\
\text { Variance } \\
\text { Extracted }\end{array}$ \\
\hline \multirow{7}{*}{ Perceived Usefulness } & PU1 & 0.868 & \multirow{7}{*}{0.880} & \multirow{7}{*}{0.909} & \multirow{7}{*}{0.599} \\
\hline & PU2 & 0.858 & & & \\
\hline & PU3 & 0.832 & & & \\
\hline & PU4 & 0.864 & & & \\
\hline & PU5 & 0.845 & & & \\
\hline & PU6 & 0.473 & & & \\
\hline & PU7 & 0.570 & & & \\
\hline \multirow{6}{*}{ Perceived Ease of Use } & PE1 & 0.840 & \multirow{6}{*}{0.920} & \multirow{6}{*}{0.937} & \multirow{6}{*}{0.714} \\
\hline & PE2 & 0.862 & & & \\
\hline & PE3 & 0.850 & & & \\
\hline & PE4 & 0.860 & & & \\
\hline & PE5 & 0.767 & & & \\
\hline & PE6 & 0.886 & & & \\
\hline \multirow{3}{*}{$\begin{array}{l}\text { Behavioral Intention to } \\
\text { Use }\end{array}$} & BI1 & 0.893 & \multirow{3}{*}{0.873} & \multirow{3}{*}{0.922} & \multirow{3}{*}{0.797} \\
\hline & BI2 & 0.894 & & & \\
\hline & $\mathrm{BI} 3$ & 0.891 & & & \\
\hline \multirow{2}{*}{ Actual Use } & AU1 & 0.912 & \multirow{2}{*}{0.814} & \multirow{2}{*}{0.915} & \multirow{2}{*}{0.843} \\
\hline & AU2 & 0.924 & & & \\
\hline
\end{tabular}

In order to establish the discriminant validity, the Fornell-Larcker criterion, cross loadings, and the Heterotrait-Monotrait Ratio should be examined. In terms of the Fornell-Larcker criterion, the square root of AVE (diagonal value) for each variable should exceed the correlation of latent variables, which is met in the present study as described in Table 3. With regard to the cross loadings, the loading of each indicator should be higher than the loadings of its corresponding variables' indicators. Based on Table 4, we can observe that the cross loadings criterion is fulfilled. Regarding the Heterotrait-Monotrait ratio (HTMT), a value of less than 0.85 for HTMT should be confirmed. According to Table 5, it can be deduced that the HTMT criterion is met, thus indicating that the discriminant validity is established.

Table 3. Fornell-Larcker Criterion Results

\begin{tabular}{|c|c|c|c|c|}
\hline & AU & BI & PEOU & PU \\
\hline AU & $\mathbf{0 . 9 1 8}$ & & & \\
\hline BI & 0.673 & $\mathbf{0 . 8 9 3}$ & & \\
\hline PEOU & 0.613 & 0.740 & $\mathbf{0 . 8 4 5}$ & \\
\hline PU & 0.589 & 0.682 & 0.772 & $\mathbf{0 . 7 7 4}$ \\
\hline
\end{tabular}


Table 4. Cross Loadings Results

\begin{tabular}{|c|c|c|c|c|}
\hline & AU & BI & PEOU & PU \\
\hline AU1 & $\mathbf{0 . 9 1 2}$ & 0.597 & 0.559 & 0.507 \\
\hline AU2 & $\mathbf{0 . 9 2 4}$ & 0.637 & 0.567 & 0.573 \\
\hline BI1 & 0.558 & $\mathbf{0 . 8 9 3}$ & 0.651 & 0.597 \\
\hline BI2 & 0.642 & $\mathbf{0 . 8 9 4}$ & 0.659 & 0.622 \\
\hline BI3 & 0.600 & $\mathbf{0 . 8 9 1}$ & 0.672 & 0.605 \\
\hline PE1 & 0.492 & 0.667 & $\mathbf{0 . 8 4 0}$ & 0.639 \\
\hline PE2 & 0.574 & 0.603 & $\mathbf{0 . 8 6 2}$ & 0.664 \\
\hline PE3 & 0.556 & 0.665 & $\mathbf{0 . 8 5 0}$ & 0.649 \\
\hline PE4 & 0.528 & 0.609 & $\mathbf{0 . 8 6 0}$ & 0.674 \\
\hline PE5 & 0.411 & 0.536 & $\mathbf{0 . 7 6 7}$ & 0.603 \\
\hline PE6 & 0.540 & 0.664 & $\mathbf{0 . 8 8 6}$ & 0.684 \\
\hline PU1 & 0.542 & 0.607 & 0.698 & $\mathbf{0 . 8 6 8}$ \\
\hline PU2 & 0.513 & 0.575 & 0.642 & $\mathbf{0 . 8 5 8}$ \\
\hline PU3 & 0.480 & 0.547 & 0.683 & $\mathbf{0 . 8 3 2}$ \\
\hline PU4 & 0.498 & 0.558 & 0.667 & $\mathbf{0 . 8 6 4}$ \\
\hline PU5 & 0.447 & 0.539 & 0.645 & $\mathbf{0 . 8 4 5}$ \\
\hline
\end{tabular}

Table 5. Heterotrait-Monotrait ratio (HTMT) Results

\begin{tabular}{|c|c|c|c|c|}
\hline & AU & BI & PEOU & PU \\
\hline AU & & & & \\
\hline BI & 0.797 & & & \\
\hline PEOU & 0.707 & 0.825 & & \\
\hline PU & 0.695 & 0.782 & 0.848 & \\
\hline
\end{tabular}

\subsection{Structural Model Assessment}

The explanatory power of the model is evaluated by measuring the discrepancy amount in the dependent variables of the model. According to [17], the $R^{2}$ and the path coefficients are the essential measures for assessing the structural model. As shown in Figure 1, the model has $R^{2}$ value of $58.7 \%$ for PU, $56.4 \%$ for BI, and $45.3 \%$ for AU.

In terms of path analysis, Figure 1 and Table 6 demonstrate the path coefficients and $p$-values for each hypothesis. It can be noticed that all the hypotheses are supported, which in turn indicates that all the paths are significant between the independent and dependent variables. $\mathbf{H}_{1}(B=0.766, p<0.05)$ describes the path between perceived ease of use and perceived usefulness; indicating that the perceived ease of use enhances the perceived usefulness of Google classroom. $\mathbf{H}_{2}(B=0.588, p<0.05)$ shows the path between perceived ease of use and behavioral intention; representing that the perceived ease of use leverages the behavioral intention to use Google classrooms. $\mathbf{H}_{3}(B=0.199, p<0.05)$ demonstrates the path between perceived usefulness and behavioral intention; revealing that perceived usefulness positively influences the 


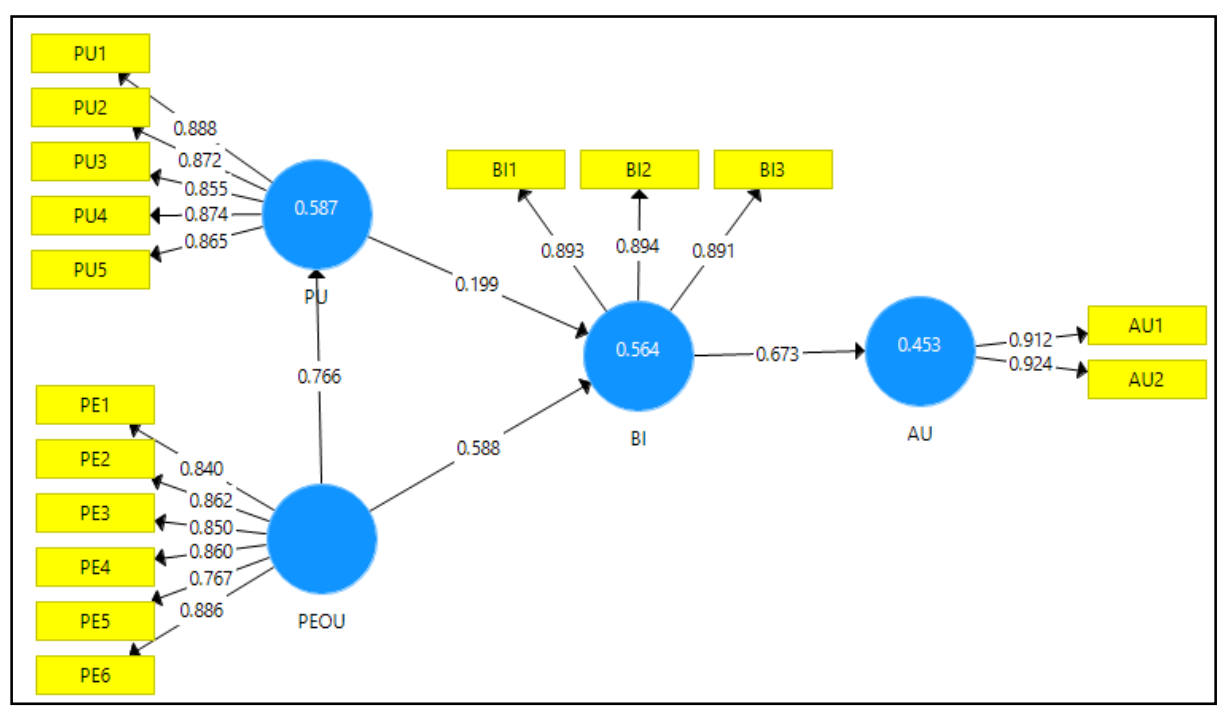

Fig. 1. Path Analysis Results

Table 6. Hypotheses Test Results

\begin{tabular}{|c|c|c|c|l|}
\hline Hypothesis & Path & Path Coefficient & $\boldsymbol{p}$-value & Remarks \\
\hline $\boldsymbol{H} \mathbf{1}$ & PEOU $\rightarrow$ PU & 0.766 & 0.000 & Supported \\
\hline $\boldsymbol{H} \mathbf{H}$ & PEOU $\rightarrow \mathrm{BI}$ & 0.588 & 0.000 & Supported \\
\hline $\boldsymbol{H} 3$ & $\mathrm{PU} \rightarrow \mathrm{BI}$ & 0.199 & 0.003 & Supported \\
\hline $\boldsymbol{H} 4$ & $\mathrm{BI} \rightarrow \mathrm{AU}$ & 0.673 & 0.000 & Supported \\
\hline
\end{tabular}

behavioral intention to use Google classrooms. $\mathbf{H}_{4}(B=0.673, p<0.05)$ describes the path between behavioral intention and actual usage; indicating that behavioral intention is significantly affecting the actual usage of Google classrooms.

The results of this research study suggest that both PEOU and PU positively affect the behavioral intention by undergraduates' students who perceive the use of Google classrooms as easy and useful, and they are highly motivated toward the incorporation of such pedagogical tools in their learning process. Similarly, a study by [3] found that PEOU and PU positively affect the students' satisfaction toward adopting Google classrooms in the learning process. Thus, it can be concluded that PEOU and PU enhance the behavioral intention to use Google classrooms. In addition, the decision makers of the higher educational institutions should take these results into their consideration in their future attempt to construct Google classroom infrastructure.

\section{Conclusion and future work}

This study determines the factors affecting Google classroom acceptance among the undergraduates' students at BUC by adopting the TAM. The PLS-SEM approach 
is used to assess the measurement and structural models. The outcomes reveal that all the factors are significantly effective in terms of both the behavioral intention and the actual usage of Google classrooms. The emphasis is placed on the familiarity in usefulness and ease of use as crucial features of Google classroom. These two features affect significantly the chosen sample of undergraduates' intention as Google classroom works as a facilitator to develop their learning activities.

One of the outstanding results that can be of great importance to any decision makers in academic institutions is the fact that the students who rely on Google classroom technology will be able to use it as a new gadget for leveraging their educational system. This conclusion is supported by BUC students' high reliance on this technology due to the previously mentioned factors which are the ease of use and usefulness. Accordingly, the decision makers of the higher educational institutions should acknowledge the features of Google classrooms and build their infrastructure based on the result achieved in this study. To implement this technology practically, the higher educational institutions should provide the students with training-opportunities so that students' abilities to discover the comprehensive and effective features of Google classrooms will be more apparent and implemented widely by the end-users.

Due to the fact, each study has a few limitations. The limitations of this study could be summarized as follows: first, this study adopts the TAM factors with no further extensions. Hence, further research should focus on determining further factors that may influence the acceptance of Google classrooms. Second, the data was collected from BUC students only, thus, the results could not be generalized to all the higher educational institutions in Oman. Therefore, further research is required to collect data from other colleges and universities in Oman in order to increase the generalizability of the results. Third, the data collection was constrained on students only. Thus, future research should involve the faculty members in order to understand the factors that affect their Google classroom acceptance.

\section{Appendix A. Constructs' items}

Perceived Usefulness

PU1: Google Classroom enhances my efficiency.

PU2: Google Classroom enhances my learning productivity.

PU3: Google Classroom enables me to accomplish tasks more quickly.

PU4: Google Classroom improves my performance.

PU5: Google Classroom saves my time.

PU6: Google Classroom doesn't have any distinctive useful features.

PU7: Google Classroom is not applicable to all academic courses.

Perceived Ease of Use

PE1: Google Classroom is easy to use.

PE2: Google Classroom enables me to access the course material.

PE3: Google Classroom is convenient and user-friendly.

PE4: Google Classroom allows me to submit my assignments. 
PE5: Google Classroom requires no training.

PE6: Google Classroom makes it easier to avoid future academic difficulties.

Behavioral Intention to Use

BI1: I intend to increase my use of the Google Classroom.

BI2: It is worth to recommend the Google Classroom for other students.

BI3: I'm interested to use the Google Classroom more frequently in the future.

Actual System Use

AU1: I use the Google Classroom on daily basis.

AU2: I use the Google Classroom frequently.

\section{$8 \quad$ References}

[1] J. E. Gallagher, K. A. Dobrosielski-vergona, R. G. Wingard, and T. M. Williams, "Webbased vs . Traditional Classroom Instruction in Gerontology: A Pilot Study," vol. 79, no. 3, pp. 1-10, 2005.

[2] S. Latif, "Learning Engagement in Virtual Environment," vol. 148, no. 11, pp. 7-13, 2016.

[3] I. N. M. Shaharanee, J. M. Jamil, and S. S. M. Rodzi, "The Application of Google Classroom as a Tool for Teaching and Learning," vol. 8, no. 10, pp. 5-8, 2016.

[4] P. Jakkaew and S. Hemrungrote, "The Use of UTAUT2 Model for Understanding Student Perceptions Using Google Classroom: A Case Study of Introduction to Information Technology Course," in Digital Arts, Media and Technology (ICDAMT), International Conference, 2017, pp. 205-209. https://doi.org/10.1109/ICDAMT.2017.7904962

[5] S. Iftakhar, "Google classroom: what works and how?," J. Educ. Soc. Sci., vol. 3, no. Feb, pp. 12-18, 2016.

[6] K. M. Dicicco, "The effects of Google Classroom on teaching social studies for students with learning disabilities," Rowan University, 2016.

[7] S. Hemrungrote, P. Jakkaew, and S. Assawaboonmee, "Deployment of Google Classroom to Enhance SDL Cognitive Skills: A Case Study of Introduction to Information Technology Course," in Digital Arts, Media and Technology (ICDAMT), International Conference, 2017, pp. 200-204. https://doi.org/10.1109/ICDAMT.2017.7904961

[8] M. Al Emran and K. Shaalan, "E-podium Technology: A medium of managing Knowledge at Al Buraimi University College via M-learning," in BCS International IT Conference, 2014, pp. 1-4.

[9] M. Al-Emran and S. A. Salloum, "Students' Attitudes Towards the Use of Mobile Technologies in e-Evaluation," Int. J. Interact. Mob. Technol., vol. 11, no. 5, pp. 195-202, 2017. https://doi.org/10.3991/ijim.v11i5.6879

[10] M. Al-Emran and K. Shaalan, "Academics' Awareness Towards Mobile Learning in Oman," Int. J. Comput. Digit. Syst., vol. 6, no. 1, pp. 45-50, 2017. https://doi.org/10.12785/IJCDS/060105

[11] M. Al-Emran and S. I. Malik, "The Impact of Google Apps at Work: Higher Educational Perspective," Int. J. Interact. Mob. Technol., vol. 10, no. 4, pp. 85-88, 2016. https://doi.org/10.3991/ijim.v10i4.6181 
[12] F. D. F. Davis, "Perceived usefulness, perceived ease of use, and user acceptance of information technology," MIS Q., vol. 13, no. 3, pp. 319-340, 1989. https://doi.org/10.2307/249008

[13] I. Fishbein, M. \& Ajzen, "Belief, attitude, attitude, intention and behavior: An introduction to theory of research," Reading, MA Addison-Wesley Addison-Wesley, p. 578, 1975.

[14] T. Almarabeh, "Students' perceptions of E-learning at the University of Jordan," Int. J. Emerg. Technol. Learn., vol. 9, no. 3, pp. 31-35, 2014. https://doi.org/10.3991/ ijet.v9i3.3347

[15] M. Al-Emran, H. M. Elsherif, and K. Shaalan, "Investigating attitudes towards the use of mobile learning in higher education," Comput. Human Behav., vol. 56, pp. 93-102, 2016. https://doi.org/10.1016/j.chb.2015.11.033

[16] C. M. Ringle, S. Wende, and J.-M. Becker, "SmartPLS 3. Bönningstedt: SmartPLS.” 2015.

[17] J. F. Hair, G. T. M. Hult, C. Ringle, and M. Sarstedt, A PRIMER ON PARTIAL LEAST SQUARES STRUCTURAL EQUATION MODELING (PLS-SEM). Sage Publications, 2014.

[18] J. Henseler, C. M. Ringle, and M. Sarstedt, "A new criterion for assessing discriminant validity in variance-based structural equation modeling," J. Acad. Mark. Sci., vol. 43, no. 1, pp. 115-135, 2015. https://doi.org/10.1007/s11747-014-0403-8

\section{Authors}

Rana A. Saeed Al-Maroof is specialized in English Language and linguistics. She is currently employed at Al Buraimi University College in Oman, as Assistant professor in the English Language Department. Her experience is extensive and diverse from teaching classes start up to successful highly developed administration duties. She has published papers particularly in the field of "Contrastive linguistics", "Discourse Analysis" and "E-learning". Her research field of interest is discourse analysis. She is interested in application of several models to a specific type of texts. Religious texts are the core of her interest. The approach that is followed in her research is to merge previously suggested models under a new model that is designed to measure the availability of certain aspects in a specific text.

Mostafa Al-Emran is a PhD student in Computer Science at Universiti Malaysia Pahang. He got his MSc in Informatics from The British University in Dubai with a distinction level along with the top Academic Excellence Award. Al-Emran got his Bachelor degree from Al Buraimi University College with the first honor degree in Computer Science. Currently, He is the head of technical support and electronic services sections at Al Buraimi University College. Most of his publications were indexed under ISI Web of Science and Scopus. His current research interests include Mobile Learning, Knowledge Management, Technology Adoption \& Acceptance, and Text Mining.

Article submitted 21 January 2018. Resubmitted 25 February 2018. Final acceptance 25 April 2018. Final version published as submitted by the authors. 